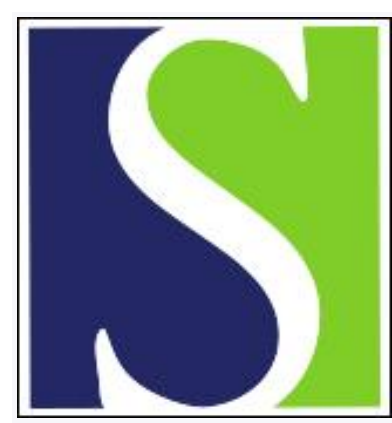

Scand J Work Environ Health 1988;14(5):312-316

https://doi.org/10.5271/sjweh.1914

Issue date: Oct 1988

Effects of low- and high-frequency local vibration on the occurrence of intimal thickening of the peripheral arteries of rats.

by Inaba R, Furuno T, Okada A

Affiliation: Department of Public Health, School of Medicine, Kanazawa University, Japan.

This article in PubMed: www.ncbi.nlm.nih.gov/pubmed/3201191

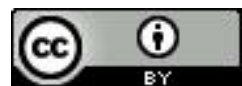




\title{
Effects of low- and high-frequency local vibration on the occurrence of intimal thickening of the peripheral arteries of rats
}

\author{
by Ryoichi Inaba, DMedSc, Toshio Furuno, DMedSc, Akira Okada, DMedSc ${ }^{1}$
}

\begin{abstract}
INABA R, FURUNO T, OKADA A. Effects of low- and high-frequency local vibration on the occurrence of intimal thickening of the peripheral arteries of rats. Scand J Work Environ Health 14 (1988) $312-316$. Rats were exposed to local vibration in a study of the differences in the effects between low and high frequencies of vibration on the vessel wall of peripheral arteries. The vibration was delivered at frequencies of 30 and $480 \mathrm{~Hz}$ under a constant acceleration of $5 \mathrm{~g}$. The duration of the vibration exposure was $30 \mathrm{~d}$. The changes in the arteries were studied pathohistologically and hematologically. Three of the five rats exposed to $30 \mathrm{~Hz}$ and three of the five rats exposed to $480 \mathrm{~Hz}$ showed disruption of the internal elastic lamina. The disruption was followed by focal cell proliferation with regenerative formation of collagen and elastic fibers. The vascular changes observed after vibration exposure could not be explained by changes in plasma lipid concentrations. These results suggest that not only low frequencies of vibration, but also high frequencies have harmful effects on the intima of small arteries.
\end{abstract}

Key terms: blood vessel, comparative study, hand-arm vibration syndrome, plasma lipid, whole blood viscosity.

Prolonged exposure to hand-arm vibration produces Raynaud's phenomenon, which is one of the main symptoms of the vibration syndrome. The mechanism leading to Raynaud's phenomenon in vibration syndrome is not yet well understood. So far, conclusive evidence for this mechanism is lacking.

Some investigators $(2,5,9)$ have reported histological changes in the peripheral arteries of workers who had used vibrating tools and had experienced Raynaud's phenomenon. It is necessary, however, to ascertain experimentally whether or not these changes are specific to exposure to local vibration. Recently, we (7) demonstrated experimentally the occurrence of intimal thickening in peripheral arteries of rats after $90 \mathrm{~d}$ of exposure to local vibration $(60 \mathrm{~Hz})$. It is also important in the investigation of vibration hazards to determine the frequencies which may have serious effects on the arteries. The purpose of the present study was to determine the differences in the effects of low and high frequencies of vibration on the occurrence of intimal thickening in the peripheral arteries of rats after $30 \mathrm{~d}$ of exposure to local vibration.

\section{Material and methods}

Twenty-one male Wistar rats, initially weighing $230-$ $250 \mathrm{~g}$, were used in groups of five or six.

\footnotetext{
1 Department of Public Health, School of Medicine, Kanazawa University, Kanazawa, Japan.
}

Reprint requests to: Dr $\mathrm{R}$ Inaba, Department of Public Health, School of Medicine, Kanazawa University, Takaramachi 13-1, Kanazawa, 920 Japan.
The apparatus used to induce vibration comprised an electromagnetic shaker (Emic 513-A) with a shaking power of $7.5 \mathrm{~kg}$ (vibration frequency range $5-5000$ $\mathrm{Hz}$ ) coupled to an amplifier (Tachikawa TA-100), a function oscillator (Torio AG202), and a vibration meter (Emic 505-D).

The animals were placed prone in individual mesh cages. Their hind legs were outside the cage, and the plantar surfaces were horizontally fixed to the vibrating plate by means of double-sided adhesive tape so that the vibration would be transmitted only to the hind legs. The part of the cage containing the rest of the animal was fixed on a nonvibrating plate separated from the shaker. The hind legs of the rats were exposed to vertical sinusoidal vibration with frequencies of $30 \mathrm{~Hz}$ and $480 \mathrm{~Hz}$ under a constant acceleration of $5 \mathrm{~g}$. The duration of exposure was $4 \mathrm{~h} / \mathrm{d}$ for $30 \mathrm{~d}$. The control animals for each experiment were also placed in the same position as the exposed animals in wire mesh cages, which were placed near the electromagnetic shaker during the exposure experiment $4 \mathrm{~h} / \mathrm{d}$ for $30 \mathrm{~d}$ so that any noise produced would be experienced but not the vibration.

Before the experiments the rats were trained for one week to ride on the vibrating platform.

The temperature in the laboratory room was kept at 18 to $22^{\circ} \mathrm{C}$ and a 12 -h "light-dark" cycle was maintained in the animal room. Food and water were provided freely each day before and after the period of vibration.

Eighteen hours after the last exposure, blood was collected into heparinized tubes after the rats were decapitated. The blood was used for measuring the whole blood viscosity, hematocrit, and plasma lipid 

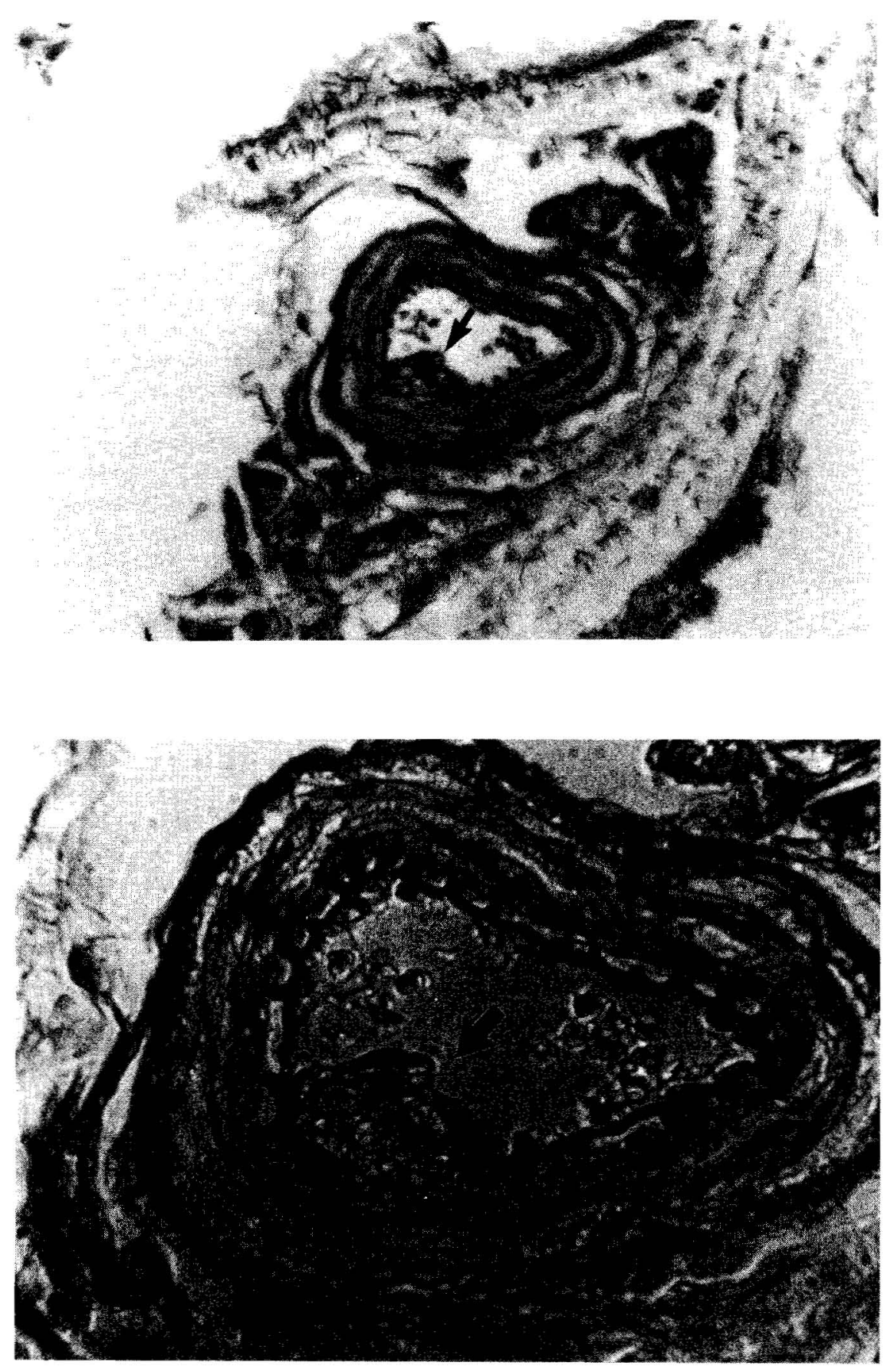

Figure 1. Small artery of the hind leg of a rat after exposure to local vibration $(30 \mathrm{~Hz}, 5 \mathrm{~g}), 4 \mathrm{~h} / \mathrm{d}$ for $30 \mathrm{~d}$. [Elastica-Van Gieson stain; magnification: upper figure 330x, lower figure 550x].

components [total cholesterol, high density lipoprotein (HDL) cholesterol, and lipoperoxide].

For the microscopic examination, cross-sections of the foot, $1.5 \mathrm{~cm}$ peripheral from the ankle, were obtained and were stained with hematoxylin-eosin and elastica-Van Gieson.
Whole blood viscosity was measured with a WellsBrookfield cone plate microviscometer (model LVT) at $37^{\circ} \mathrm{C}$ at two shear rates, 115 and $230 \mathrm{~s}^{-1}$.

The plasma concentrations of total cholesterol and HDL cholesterol were measured by enzymatic methods; the plasma concentrations of lipoperoxide 
were determined with the fluorometric method developed by Yagi (11).

The statistical significance of the results was tested with Student's t-test.

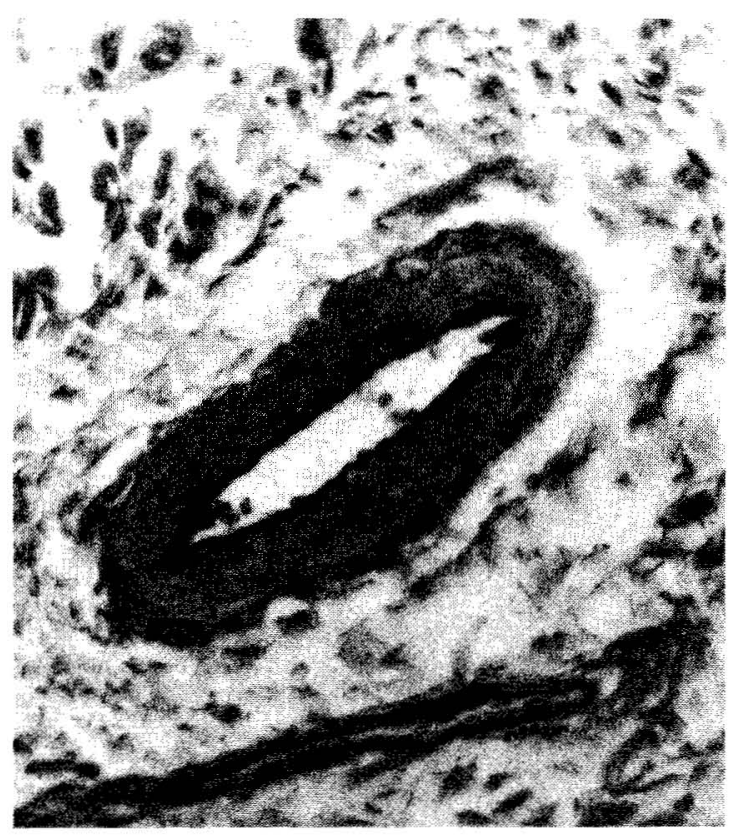

Figure 2. Normal small artery of the hind leg of a control rat. (Elastica-Van Gieson stain; magnification 330x).

\section{Results}

After $30 \mathrm{~d}$ of exposure, almost the same histological changes were observed in the small arteries at the exposed site in three of five rats exposed to $30 \mathrm{~Hz}$ and in three of five rats exposed to $480 \mathrm{~Hz}$. The changes were observed only in the intima. Namely, neither the media nor the adventitia showed any histological change. Figure 1 shows the histological changes in the artery of the hind leg of a rat after exposure to $30 \mathrm{~Hz}$ for $30 \mathrm{~d}$; disruption of internal elastic lamina and focal cell proliferation with formation of collagen and elastic fibers can be observed. These alterations were not observed in the rats of the control groups (figure 2).

Table 1 shows the effects of local vibration exposure on the whole blood viscosity measured at shear rates of 115 and $230 \mathrm{~s}^{-1}$ and on the hematocrit level. There were no significant differences in the levels of whole blood viscosity or hematocrit between the controls and the exposed groups at any frequency of exposure.

Table 2 shows the effects of local vibration exposure on the plasma lipid concentrations. There were no significant differences in the plasma concentrations of total cholesterol, HDL cholesterol or lipoperoxide between the controls and the exposed groups at any frequency of exposure.

\section{Discussion}

Takeuchi \& Imanishi (9) reported that intimal thickening was observed in skin biopsies of the fingers of

Table 1. Whole blood viscosity, measured at shear rates of 115 and $230 \mathrm{~s}^{-1}$, and hematocrit levels of rats whose hind legs were exposed to vibration $(30$ or $480 \mathrm{~Hz}$ ) for $4 \mathrm{~h} / \mathrm{d}$ for $30 \mathrm{~d}$ and of their controls.

\begin{tabular}{|c|c|c|c|c|c|c|c|}
\hline \multirow{3}{*}{ Exposure group } & \multirow{3}{*}{ Number } & \multicolumn{4}{|c|}{ Whole blood viscosity } & \multirow{2}{*}{\multicolumn{2}{|c|}{$\begin{array}{c}\text { Hematocrit } \\
(\%)\end{array}$}} \\
\hline & & \multicolumn{2}{|c|}{ Shear rate $115 \mathrm{~s}^{-1}$} & \multicolumn{2}{|c|}{ Shear rate $230 \mathrm{~s}^{-1}$} & & \\
\hline & & Mean & $\mathrm{Se}$ & Mean & SE & Mean & $\mathrm{SE}$ \\
\hline \multicolumn{8}{|l|}{$30 \mathrm{~Hz}$} \\
\hline Control rats & 6 & 4.55 & 0.18 & 3.89 & 0.12 & 42.1 & 0.3 \\
\hline Vibration-exposed rats & 5 & 4.72 & 0.22 & 3.95 & 0.14 & 42.7 & 0.8 \\
\hline \multicolumn{8}{|l|}{$480 \mathrm{~Hz}$} \\
\hline 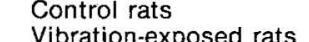 & 5 & 5.04 & 0.26 & 4.35 & 0.19 & 40.5 & 0.5 \\
\hline Vibration-exposed rats & 5 & 4.67 & 0.20 & 4.09 & 0.16 & 41.0 & 0.8 \\
\hline
\end{tabular}

Table 2. Plasma lipid concentrations of rats whose hind legs were exposed to vibration $(30$ or $480 \mathrm{~Hz}$ ) for $4 \mathrm{~h} / \mathrm{d}$ for $30 \mathrm{~d}$ and of their controls.

\begin{tabular}{|c|c|c|c|c|c|c|c|}
\hline \multirow[t]{2}{*}{ Exposure group } & \multirow[t]{2}{*}{ Number } & \multicolumn{2}{|c|}{$\begin{array}{c}\text { Total cholesterol } \\
(\mathrm{mg} / \mathrm{dl})\end{array}$} & \multicolumn{2}{|c|}{$\begin{array}{l}\text { High density } \\
\text { lipoprotein } \\
\text { cholesterol } \\
(\mathrm{mg} / \mathrm{dl})\end{array}$} & \multicolumn{2}{|c|}{$\begin{array}{l}\text { Lipoperoxide } \\
\text { (nmol/ml) }\end{array}$} \\
\hline & & Mean & SE & Mean & SE & Mean & SE \\
\hline \multicolumn{8}{|l|}{$30 \mathrm{~Hz}$} \\
\hline Control rats & 6 & 55.7 & 3.7 & 33.0 & 2.0 & 3.42 & 0.27 \\
\hline Vibration-exposed rats & 5 & 60.6 & 4.3 & 33.8 & 2.3 & 3.70 & \\
\hline \multicolumn{8}{|l|}{$480 \mathrm{~Hz}$} \\
\hline Vibration-exposed rats & 5 & 53.8 & 3.0 & 25.0 & 1.8 & 2.96 & 0.11 \\
\hline
\end{tabular}


only a few workers who used vibrating tools and who also experienced Raynaud's phenomenon. On the other hand, Ashe \& Williams (2) reported that vibrationexposed workers with intimal thickening in skin biopsies suffered from a more severe degree of Raynaud's phenomenon than those without intimal thickening. In the present study, we found that vibration exposure for only $30 \mathrm{~d}$ produced intimal thickening in the small arteries of the hind legs of rats. Therefore, the data from the present study suggest that there is some relation between intimal thickening in small arteries and attacks of Raynaud's phenomenon. In addition, our results support the theory proposed by Ashe \& Williams (2) that intimal thickening is related to the severity of the attack.

In our experiment, the total cholesterol, HDL cholesterol and lipoperoxide concentrations in plasma, which are considered to be related to atherosclerosis (12), were not significantly different between the exposed and control groups at the two frequencies of vibration studied. These results suggest that there may be no relation between plasma lipid concentrations and the intimal thickening observed after vibration exposure. Therefore, we presume that the intimal thickenings observed in our experiment were very likely caused by the vibration exposure, and they have no relation to the atherosclerotic changes that are induced by the elevation of plasma lipids.

The whole blood viscosity did not change in our experiment with any frequency of vibration after $30 \mathrm{~d}$ of exposure. Fujinaga (3) reported that, in workers who used vibrating tools and experienced Raynaud's phenomenon, the whole blood viscosity was significantly higher than that in normal workers. We (7) previously reported that the whole blood viscosity was significantly increased, and a complete stenosis of the lumen of the small artery was observed after $90 \mathrm{~d}$ of exposure at $60 \mathrm{~Hz}$. Therefore, there may be some relation between the increase in whole blood viscosity and the duration of vibration exposure and/or between the increase in whole blood viscosity and the severity of intimal thickening.

It is important to clarify the role of vibration frequency in the pathogenesis of vibration hazards. Earlier we (7) observed no histological change in the intima of the small arteries after $30 \mathrm{~d}$ of exposure at $60 \mathrm{~Hz}, 5 \mathrm{~g}$. However, in our present experiment, we found that intimal thickening in the small arteries of rats was induced by exposure not only to $30 \mathrm{~Hz}$, which is a lower frequency than $60 \mathrm{~Hz}$, but also to $480 \mathrm{~Hz}$, which is a higher frequency than $60 \mathrm{~Hz}$. These results suggest that considerably lower frequencies, as well as higher frequencies, of vibration can cause intimal thickening of small arteries. In addition, as has already been described, we (7) reported that intimal thickening in the small arteries was observed after $90 \mathrm{~d}$ of exposure at $60 \mathrm{~Hz}, 5 g$. Therefore, effects of exposure to $30 \mathrm{~Hz}$ and $480 \mathrm{~Hz}$ on the arterial intima were in- duced by a shorter period of exposure than those produced by $60 \mathrm{~Hz}$.

Hunter et al (6) reported that Raynaud's phenomenon occurred the most frequently among workers using vibrating tools with a frequency range of 33$50 \mathrm{~Hz}$. Agate \& Druett (1) have suggested that the frequency range of $40-125 \mathrm{~Hz}$ is possibly the most hazardous in the genesis of Raynaud's phenomenon. On the other hand, Gerbis et al (4) considered the frequency range from 280 to $600 \mathrm{~Hz}$ as the most dangerous. Therefore, our present study and past studies $(1,4,7)$ indicate that not only low frequencies, but also high frequencies of vibration can be potential etiologic factors for the occurrence of Raynaud's phenomenon.

Ross et al (8) reported that repetitive injury to the endothelium is important in the production of intimal thickening. Therefore, from our present results, one can assume that repetitive vibration exposure causes endothelial damage. Recently, Vanhoutte (10) proposed a new hypothesis stating that endothelial cells play a major role in the vasodilatation evoked by a number of neurohumoral substances, such as acethylcholine, substance P, catecholamines, etc. According to this hypothesis, the absence or dysfunction of the endothelium would favor the occurrence of abnormal vasoconstriction (vasospasm). We assume from this hypothesis that the dysfunction of vasodilation based on the endothelial damage caused by vibration exposure may one be of the etiologic factors of the occurrence of Raynaud's phenomenon in vibration syndrome.

\section{Acknowledgments}

We are grateful to Drs S Katsuda and Y Oda (Department of Pathology, School of Medicine, Kanazawa University) for their valuable advice.

\section{References}

1. Agate JN, Druett HA. A study of portable vibrating tools in relation to clinical effect which they produce. Br J Ind Med 4 (1947) 141-163.

2. Ashe WF, Williams N. Occupational Raynaud's II: Further studies of this disorder in uranium mine workers. Arch Environ Health 9 (1964) 425-433.

3. Fujinaga $\mathrm{H}$. Epidemiologic findings on blood viscosity. Nippon Eiseigaku Zasshi 39 (1984) 718-728.

4. Gerbis H, Gross A, Meyer-Brdnitz KR, Robinson J. Die Verhuntung von Gesundheitsschadigungen durch Anklopvachinen. Berlin 1931. Cited by L Teleky. Occupation and health: Supplement. International Labour Organization, Geneva 1938.

5. Hashimoto K, Craig RS. Acrosclerosis associated with vibration: An electron microscopic study. J Cutan Pathol 7 (1980) 373-386.

6. Hunter D, McLaughlin AIG, Perry KMA. Clinical effects on the use of pneumatic tools. $\mathrm{Br} \mathrm{J}$ Ind Med 2 (1945) $10-16$.

7. Okada A, Inaba R, Furuno T, Nohara S, Ariizumi M. Usefulness of blood parameters, especially viscosity, for 
the diagnosis and elucidation of pathogenic mechanisms of the hand-arm vibration syndrome. Scand J Work Environ Health 13 (1987) 358-362.

8. Ross R, Glomset J, Harker L. Response to injury and atherosclerosis. Am J Pathol 86 (1977) 675-684.

9. Takeuchi T, Imanishi H. Histopathologic observations in finger biopsy from thirty patients with Raynaud's phenomenon of occupational origin. J Kumamoto Med Soc 58 (1984) 56-70.

10. Vanhoutte PM. Endothelium and the control of vascu- lar tissue. News Physiol Sci 2 (1987) 18-22.

11. Yagi K. A simple fluorometric assay for lipoperoxide in blood plasma. Biochem Med 15 (1976) 212-216.

12. Yagi K, Ohkawa H, Ohishi N, Yamashita M, Nakashima T. Lesion of aortic intima caused by intravenous administration of linoleic acid and hydroperoxide. J Appl Biochem 3 (1976) 58-65.

Received for publication: 29 January 1988 